\title{
Estudo da potencialidade da substituição parcial do cimento por resíduos da construção civil em argamassa de revestimento
}

\author{
Study of the potentiality of partial replacement of cement by civil construction residues in coating
} mortar

\section{Estudio de la potencialidad de la sustitución parcial del cemento por residuos de construcción civil en mortero de revestimiento}

\section{Resumo}

O setor da construção civil tem significativa importância no desenvolvimento socioeconômico. No entanto, a extração de recursos naturais para a produção de matéria prima e a geração de resíduos durante o processo construtivo proporcionam grandes impactos ao meio ambiente. A incorporação dos resíduos de construção civil como matériaprima para a produção de argamassas é uma alternativa para a minimização dos impactos no meio ambiente. Assim sendo, este trabalho teve como objetivo avaliar a potencialidade do uso da fração predominantemente cimentícia de dois resíduos de construção civil (RCC) como substituinte parcial do cimento em argamassas de revestimento, considerando o desempenho físico e mecânico delas. Os resíduos foram coletados em dois locais distintos da cidade de Pelotas/RS, sendo o primeiro proveniente da demolição de um prédio industrial da região central (RCD), e o segundo, proveniente de uma fábrica de artefatos cimentícios (RIPM) localizada na zona norte da cidade. Para a realização do experimento, o traço de referência foi confeccionado nas proporções de 1:2:8 (cimento, cal e areia) e as substituições em massa do cimento por resíduo foram realizadas nos teores de 5, 10 e $15 \%$. Os resultados demonstraram que a incorporação de ambos os resíduos pode ser uma alternativa viável, pois proporciona argamassas com desempenho equivalentes ao da argamassa de referência.

Palavras-chave: Tecnologia da arquitetura; Argamassa mista; Resíduos de construção civil; Resistência mecânica; Desempenho físico.

\begin{abstract}
The construction sector has significant importance in socioeconomic development. However, the extraction of natural resources for the production of raw materials and the generation of waste during the construction process provide major impacts to the environment. The incorporation of civil construction waste as a raw material for the production of mortars is an alternative for minimizing impacts on the environment. Therefore, this study aimed to evaluate the potentiality of the use of the predominantly cementitious fraction of two civil construction residues (CCR) as a partial substitute for cement in coating mortars, considering their physical and mechanical performance. The waste was collected in two different locations in the city of Pelotas/RS, the first coming from the demolition of an industrial building in the central region (RCD), and the second, coming from a cementitious artifacts factory (RIPM) located in the northern part of the city. For the experiment, the reference trait was made in the proportions of 1:2:8 (cement, lime and sand) and the mass substitutions of cement by residue were performed at the levels of 5, 10 and $15 \%$. The results showed that the incorporation of both residues can be a viable alternative, because it provides mortars with performance equivalent to that of the reference mortar.
\end{abstract}

Keywords: Architecture technology; Mixed mortar; Construction waste; Mechanical resistance; Physical performance. 


\section{Resumen}

El sector de la construcción tiene una importancia significativa en el desarrollo socioeconómico. Sin embargo, la extracción de recursos naturales para la producción de materias primas y la generación de residuos durante el proceso de construcción proporcionan importantes impactos al medio ambiente. La incorporación de residuos de construcción civil como materia prima para la producción de morteros es una alternativa para minimizar los impactos sobre el medio ambiente. Por lo tanto, este estudio tuvo como objetivo evaluar la potencialidad del uso de la fracción predominantemente cementicia de dos residuos de construcción civil (CCR) como sustituto parcial del cemento en morteros de recubrimiento, considerando su desempeño físico y mecánico. Los residuos fueron recolectados en dos localidades diferentes de la ciudad de Pelotas/RS, la primera proveniente de la demolición de un edificio industrial en la región central (RCD), y la segunda, proveniente de una fábrica de artefactos cementicios (RIPM) ubicada en la parte norte de la ciudad. Para el experimento, el rasgo de referencia se realizó en proporciones de 1:2:8 (cemento, cal y arena) y las sustituciones de masa de cemento por residuo se realizaron en los niveles de 5, 10 y $15 \%$. Los resultados mostraron que la incorporación de ambos residuos puede ser una alternativa viable, ya que proporciona morteros con un rendimiento equivalente al del mortero de referencia.

Palabras clave: Tecnología de arquitectura; Mortero mixto; Residuos de construcción; Resistencia mecânica; Rendimiento físico.

\section{Introdução}

O setor da construção civil tem significativa importância para a economia, uma vez que colabora substancialmente para a oferta de empregos diretos, isto é, na própria construção civil, e de milhares de empregos indiretos em outras áreas industriais, como os da ciência e tecnologia (Vieira \& Nogueira, 2018). No entanto, esse setor é um dos que mais impactam o meio ambiente devido à quantidade de matéria-prima utilizada, à poluição sonora e à considerável quantidade de resíduos gerados (Fonseca \& Maintinguer, 2019).

Os resíduos gerados na construção civil são provenientes das mais diversas etapas construtivas de uma obra que vai desde a limpeza do terreno à fase de acabamento, como pintura e cobertura (Oliveira, Soares, Quaresma \& Adorno, 2020). Segundo o panorama da Associação Brasileira de Empresas de Limpeza Pública e Resíduos Especiais [ABRELPE] (2020), no ano de 2019 foram coletadas no Brasil 44,5 milhões de toneladas de resíduos de construção e demolição (RCD).

Desta maneira, com o propósito de minimizar a extração excessiva de recursos naturais e evitar o descarte desnecessário dos materiais, evidencia-se a necessidade de reaproveitar os resíduos gerados pela construção civil (Ribeiro, Moura \& Pirote, 2016). Com este intuito, vêm sendo desenvolvidos estudos quanto à utilização dos resíduos de construção civil incorporados em argamassas.

Braga, Brito e Veiga (2014) analisaram a viabilidade de reduzir o consumo de cimento em argamassas através da incorporação de resíduos finos presentes em agregados reciclados provenientes da trituração de concreto. Foram testados traços com proporções de 1:4, 1:5 e 1:6 (cimento e areia) em volume e teor de substituição de 15\% do cimento por resíduos para cada um deles. Os resultados mostraram um bom desempenho à compressão para o traço 1:5, com ganho de resistência de 30\%. Já, no ensaio de resistência tração na flexão, o melhor desempenho foi registrado pelo traço 1:4.

Wichrowska, Kazberuk e Pawluczuk (2020) testaram o comportamento do resíduo de concreto como substituinte do aglomerante em argamassas de cimento e areia. As argamassas foram confeccionadas com traço em massa 1:3 e com teor de substituição de $25 \%$ do cimento por resíduo. Os resultados mostraram a viabilidade do uso do resíduo como substituto parcial do cimento ou como aditivo pozolânico para compósitos de cimento.

Formigoni, Godinho, Junca e Antunes (2019) estudaram a substituição do cimento Portland por resíduo de placa cerâmica em argamassa, sendo que as substituições ocorreram nos teores de 5, 12 e 20\% (em volume). Os resultados foram promissores para as argamassas produzidas com substituição de 5 e $12 \%$ do cimento pelo resíduo, indicando a possibilidade de seu uso.

Pinz, Paliga e Torres (2020) avaliaram a possibilidade da utilização do resíduo de cerâmica vermelha (RCV), como substituinte do agregado miúdo ou do cimento, em argamassas mistas de traços 1:2:8 e 1:2:9 (em massa). Para a substituição 
do cimento a análise foi efetuada nos teores de 5 e 10\%, e a substituição do agregado foi realizada nos teores de 10, 15 e $20 \%$. Os resultados mostraram que as argamassas confeccionadas com traço 1:2:8 apresentaram desempenho superior quando comparadas com as argamassas confeccionadas com o traço 1:2:9.

Da mesma forma, Samadi et al. (2020) avaliaram os efeitos da substituição parcial do cimento e dos agregados finos por resíduos cerâmicos. Os teores de substituição em relação à massa do cimento variaram de 10 a $60 \%$, com intervalo de substituição de $10 \%$ entre os traços. Já as substituições dos agregados finos aconteceram nos teores de 25, 50, 75 e $100 \%$ de sua massa. Os resultados mostraram que as argamassas com resíduos apresentarem desempenho inicial inferior aos da argamassa de referência. Aos 28 dias, os traços com 20 e $40 \%$ de substituição do cimento demonstraram resistência superior ao traço de referência.

Existem várias possibilidades de aplicações para o RCC em argamassas, podendo ser tanto para revestimento quanto para o assentamento. No entanto, por se tratar de um material heterogêneo com diferentes granulometrias e distintas propriedades, faz-se necessário a realização de uma exaustiva análise para garantir um material alternativo de qualidade (Jochem, 2012). Evangelista, Guedes, Brito, Ferro e Pereira (2015) acrescentam que esses materiais têm alta capacidade de absorção de água e podem conter contaminantes provenientes do processo de reciclagem.

Além disso, os resíduos podem influenciar na zona de transição dos materiais, que é considerada o elo mais fraco no material cimentício. No estudo de Jochem (2017), a autora constatou que a presença da antiga matriz de cimento no agregado reciclado resultou em uma microestrutura distinta das misturas que utilizaram agregado natural.

Tendo em consideração a importância do desenvolvimento de tecnologias alternativas que minimizem os impactos causados pelo consumo de recursos naturais para a produção de matéria-prima e, ao mesmo tempo, que possibilitem a reutilização dos resíduos de construção civil, este trabalho teve como objetivo avaliar a potencialidade da substituição parcial do cimento por dois resíduos de construção civil (RCC) em argamassas de revestimento, considerando o seu desempenho físico (absorção por capilaridade, absorção por imersão e índices de vazios) e mecânico (resistência à compressão axial e resistência à tração na flexão).

\section{Metodologia}

Para o desenvolvimento desta pesquisa foram coletados em locais distintos na cidade de Pelotas/RS dois resíduos de construção civil. O primeiro material oriundo da demolição de um prédio industrial e o segundo material foi coletado em uma indústria de artefatos cimentícios. A coleta dos resíduos seguiu as recomendações da NBR 10007/2015 (Amostragem de resíduos sólidos).

O primeiro resíduo coletado (RCD) era composto de material cerâmico, concreto, argamassa, madeira e aço. Desta forma, no ambiente de laboratório esse resíduo passou por uma seleção prévia, separando apenas fragmentos de concreto e argamassas. Na sequência, com finalidade de reduzir a granulometria das partículas e tornar possível a aplicação em argamassas, ambos os resíduos foram beneficiados em britador de mandíbulas verticais (Marconi, modelo MA 2015), 380 RPM e abertura mínima entre as mandíbulas de $1 \mathrm{~mm}$, conforme apresentado na Figura 1. 
Figura 1. Triturado de mandíbulas vertical.

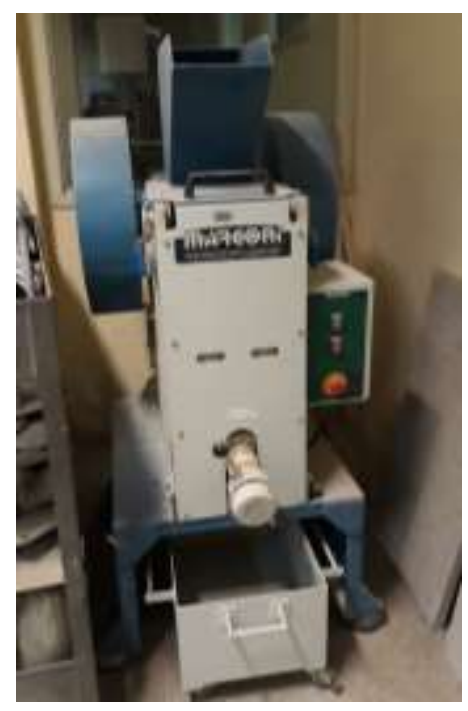

Fonte: Autores (2021).

Além dos resíduos, foram utilizados para compor a mistura o cimento Portland CP IV 32, comumente utilizado em obras da região sul do estado do Rio Grande do Sul, cal hidratada, areia média quartzosa lavada, água proveniente da Companhia Rio-grandense de Saneamento - CORSAN, companhia de fornecimento de água e dois resíduos de construção civil.

A Tabela 1 apresenta as características físicas, mecânicas e químicas do cimento Portland CP IV 32, conforme informações do fabricante.

Tabela 1. Características físicas, mecânicas e químicas do cimento.

\begin{tabular}{|c|c|c|c|}
\hline Características & \multicolumn{2}{|c|}{ Tipo de ensaio } & Resultados \\
\hline \multirow{9}{*}{$\begin{array}{l}\text { Físicas e } \\
\text { Mecânicas }\end{array}$} & \multicolumn{2}{|c|}{ Massa específica $\left(\mathrm{g} / \mathrm{cm}^{3}\right)$} & 2,77 \\
\hline & \multirow{2}{*}{ Finura $(\%)$} & \# 200 & 0,6 \\
\hline & & \# 325 & 2,8 \\
\hline & \multicolumn{2}{|c|}{ Blaine $\left(\mathrm{cm}^{2} / \mathrm{g}\right)$} & 4252 \\
\hline & \multirow{2}{*}{ Tempo de Pega (min) } & Início de Pega & 286,8 \\
\hline & & Fim de Pega & 355 \\
\hline & \multirow{3}{*}{ Resistência à compressão (MPa) } & 3 dias & 20,2 \\
\hline & & 7 dias & 24,80 \\
\hline & & 28 dias & 39,00 \\
\hline \multirow{4}{*}{ Químicas } & \multicolumn{2}{|c|}{ Resíduo Insolúvel (\%) } & 36,2 \\
\hline & \multicolumn{2}{|c|}{ Perda ao Fogo $(\%)$} & 2,90 \\
\hline & \multicolumn{2}{|l|}{$\mathrm{SO} 3$} & 1,90 \\
\hline & \multicolumn{2}{|l|}{$\operatorname{MgO}(\%)$} & 4,80 \\
\hline
\end{tabular}

Fonte: Votorantim Cimentos (2020).

A Tabela 2 apresenta as características físicas e químicas da cal, conforme informações do fabricante. 
Tabela 2. Características físicas e químicas da cal hidratada.

\begin{tabular}{|c|c|c|}
\hline Química & \multicolumn{2}{|c|}{ Análise (\%) } \\
\hline Óxidos Totais & \multicolumn{2}{|c|}{$\leq 88$} \\
\hline Óxidos não hidratados & \multicolumn{2}{|c|}{$\leq 15$} \\
\hline $\mathrm{CaO}$ - Óxido de Cálcio & \multicolumn{2}{|c|}{43,06} \\
\hline $\mathrm{MgO}$ - Óxido de Magnésio & \multicolumn{2}{|c|}{26,63} \\
\hline R I - Resíduos Insolúveis & \multicolumn{2}{|c|}{8,07} \\
\hline P F - Perda ao Fogo & \multicolumn{2}{|c|}{22,11} \\
\hline Umidade & \multicolumn{2}{|c|}{0,66} \\
\hline Densidade (g/l) & \multicolumn{2}{|c|}{538} \\
\hline \multirow{2}{*}{ Física } & \multicolumn{2}{|c|}{ Análise (\%) } \\
\hline & Limites & Análises \\
\hline Peneira $0,6 \mathrm{~mm}$ & 0,50 & 0,00 \\
\hline Peneira $0,075 \mathrm{~mm}$ & 15 & 9,67 \\
\hline
\end{tabular}

Fonte: Dagoberto Barcellos (2020)

Já a areia e os resíduos passaram por ensaios de caracterização seguindo as recomendações das normas vigentes da ABNT. Os resultados destes ensaios podem ser consultados na Tabela 3.

Tabela 3. Parâmetros físicos avaliados

\begin{tabular}{|c|c|c|c|c|}
\hline Parâmetros físicos & & RCD & RIPM & AREIA \\
\hline Massa específica (NBR NM 52/2009) & & $2,51 \mathrm{~g} / \mathrm{cm}^{3}$ & $2,33 \mathrm{~g} / \mathrm{cm}^{3}$ & $2,41 \mathrm{~g} / \mathrm{cm}^{3}$ \\
\hline Massa unitária solta (NBR NM 45/2006 & & $1,46 \mathrm{~g} / \mathrm{cm}^{3}$ & $1,56 \mathrm{~g} / \mathrm{cm}^{3}$ & $1,49 \mathrm{~g} / \mathrm{cm}^{3}$ \\
\hline Índice de volume de vazios (NBR NM 45/2 & 006) & $30,5 \%$ & $25,4 \%$ & $31,24 \%$ \\
\hline Absorção (NBR NM 30/2001) & & $8 \%$ & $4,7 \%$ & $0,61 \%$ \\
\hline \multirow{2}{*}{ Composição granulométrica (NBR NM 248 /2003) } & Mód. Finura & 3,32 & 3,09 & 2,79 \\
\hline & $\overline{\emptyset \text { máx. }(\mathrm{mm})}$ & 6,3 & 6,3 & 4,8 \\
\hline
\end{tabular}

Fonte: Autores (2021).

Foi utilizado como traço de referência as proporções em massa de 1:2:8 (cimento, cal e areia), e teores de substituição do cimento por resíduo de 5, 10 e 15\%, de acordo com Pinz (2019). A Tabela 4 apresenta a quantidade de material utilizado para cada ensaio realizado.

Tabela 4. Quantidade de material utilizado em cada ensaio.

\begin{tabular}{ccccc}
\hline Traço & Cimento $(\mathbf{g})$ & Resíduo $(\mathbf{g})$ & Cal $(\mathbf{g})$ & Areia $(\mathbf{g})$ \\
\hline REF & 156 & 0 & 312 & 1248 \\
\hline RCD 5\% & 148,20 & 7,80 & 312 & 1248 \\
\hline RCD 10\% & 140,40 & 15,60 & 312 & 1248 \\
\hline RCD 15\% & 132,60 & 23,40 & 312 & 1248 \\
\hline RIPM 5\% & 148,20 & 7,80 & 312 & 1248 \\
\hline RIPM 10\% & 140,40 & 15,60 & 312 & 1248 \\
\hline RIPM 15\% & 132,60 & 23,40 & 312 & 1248 \\
\hline
\end{tabular}

Fonte: Autores (2021). 
Para a confecção dos corpos de prova, os resíduos e a areia foram peneirados e divididos em frações. A areia foi separada em quatro porções, conforme determina a NBR 7214/2015 (Areia normal para ensaio de cimento - Especificação), sendo elas: grossa, retida na peneira $1,18 \mathrm{~mm}$; média-grossa, retida na peneira $0,6 \mathrm{~mm}$; média-fina, retida na peneira $0,3 \mathrm{~mm}$ e fina, retida na peneira $0,15 \mathrm{~mm}$. Já dos resíduos, foram selecionados, apenas os materiais que passaram na peneira $0,15 \mathrm{~mm}$ e ficaram retidos na peneira $45 \mu \mathrm{m}$.

O preparo da argamassa seguiu os procedimentos de execução prescritos na NBR 13276/2016 (Argamassa para assentamento e revestimento de paredes e tetos - Determinação do índice de consistência), com auxílio de uma argamassadeira automática de movimento planetário de duas velocidades (Projetest). Considerando que os resíduos apresentaram índices de absorção distintos, delimitou-se o índice de consistência de $260 \mathrm{~mm} \pm 5 \mathrm{~mm}$, sendo assim, o consumo de água variou para atender a este parâmetro, e a verificação foi realizada com auxílio de um paquímetro (Figura 2). A Tabela 5 apresenta os traços desenvolvidos e a relação água aglomerante de cada uma das misturas.

Figura 2. Verificação do índice de consistência.

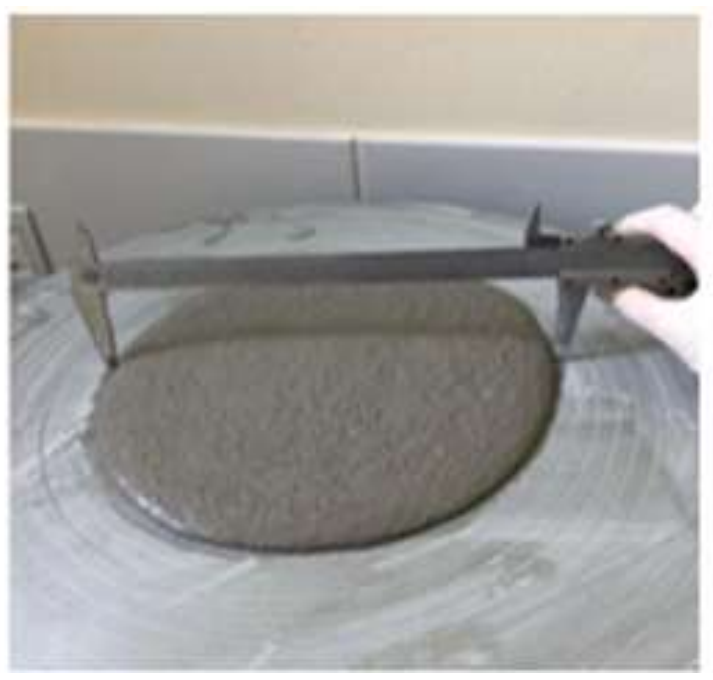

Fonte: Autores (2021).

Tabela 5. Relação água aglomerante e índice de consistência.

\begin{tabular}{ccc}
\hline Traço & Relação Água/aglomerante & Índice de consistência \\
\hline REF & 0,74 & 255 \\
\hline RCD 5\% & 0,70 & 262 \\
\hline RCD 10\% & 0,71 & 265 \\
\hline RCD 15\% & 0,72 & 260 \\
\hline RIPM 5\% & 0,72 & 265 \\
\hline RIPM 10\% & 0,71 & 260 \\
\hline RIPM 15\% & 0,73 & 265 \\
\hline
\end{tabular}

Fonte: Autores (2021).

As argamassas passaram por testes de desempenhos físicos (ensaios de absorção por capilaridade, absorção por imersão e índices de vazios) e mecânicos (ensaio de resistência à compressão axial e resistência à tração na flexão). A Tabela 6 indica os parâmetros que foram avaliados neste estudo, bem como a idade de execução de cada ensaio e o número de corpos de prova. 
Tabela 6. Parâmetros avaliados

\begin{tabular}{ccc}
\hline Parâmetro avaliado & $\begin{array}{c}\text { Idade dos corpos de prova } \\
\text { na data ensaio (dias) }\end{array}$ & $\begin{array}{c}\text { Número de } \\
\text { corpos de prova }\end{array}$ \\
\hline Resistência à compressão axial (NBR 7215/2019) & 7,28 e 63 & 4 por idade \\
\hline Resistência à tração por flexão (NBR 13279/2005) & 28 & 3 \\
\hline Absorção por capilaridade (NBR 9779/2012) & 28 & 3 \\
\hline Absorção por imersão e índice de vazios (NBR 9778/2009) & 28 & 2 \\
\hline
\end{tabular}

Fonte: Autores (2021).

Após a execução do ensaio, os resultados passaram pela análise de variância (ANOVA) com nível de significância de 5\%. Essa análise permite verificar se há diferenças significativas entre os grupos avaliados, no entanto, não identifica entre quais grupos a diferença é significativa. Para identificar as médias diferentes, realizou-se o teste de Tukey com intervalo de confiança de $95 \%$. Com base nesses resultados pôde-se determinar o melhor teor de substituição.

\section{Resultados e Discussão}

Os resultados serão apresentados em duas seções: desempenho mecânico (resistência à compressão axial e resistência à tração na flexão) e desempenho físico (absorção por capilaridade, absorção por imersão e índice de vazios).

\subsection{Desempenho mecânico}

O ensaio de resistência à compressão axial foi realizado nas idades de 7, 28 e 63 dias. A Tabela 7 apresenta os resultados de médias, desvio padrão e coeficiente de variação das argamassas estudadas.

Tabela 7. Resultado da resistência à compressão em todas as idades.

\begin{tabular}{|c|c|c|c|c|c|c|c|c|c|}
\hline \multirow[b]{2}{*}{ Traço } & \multicolumn{3}{|c|}{7 dias } & \multicolumn{3}{|c|}{28 dias } & \multicolumn{3}{|c|}{63 dias } \\
\hline & $\begin{array}{l}\text { Média } \\
\text { (Mpa) }\end{array}$ & $\begin{array}{c}\text { Desvio } \\
\text { Padrão } \\
\text { (Mpa) }\end{array}$ & $\begin{array}{c}\text { Coef. } \\
\text { Variação } \\
(\%) \\
\end{array}$ & $\begin{array}{l}\text { Média } \\
\text { (Mpa) }\end{array}$ & $\begin{array}{c}\text { Desvio } \\
\text { Padrão } \\
\text { (Mpa) }\end{array}$ & $\begin{array}{c}\text { Coef. } \\
\text { Variação } \\
(\%) \\
\end{array}$ & $\begin{array}{l}\text { Média } \\
\text { (Mpa) }\end{array}$ & $\begin{array}{c}\text { Desvio } \\
\text { Padrão } \\
\text { (Mpa) }\end{array}$ & $\begin{array}{c}\text { Coef. } \\
\text { Variação } \\
(\%) \\
\end{array}$ \\
\hline $\mathrm{REF}$ & 1,92 & 0,10 & 5,46 & 6,16 & 0,74 & 12,05 & 9,71 & 1,32 & 13,55 \\
\hline RIPM 5\% & 1,76 & 0,05 & 2,90 & 5,61 & 0,60 & 10,61 & 7,64 & 0,25 & 3,27 \\
\hline RIPM 10\% & 1,81 & 0,09 & 4,88 & 5,35 & 0,22 & 4,04 & 7,60 & 0,23 & 3,06 \\
\hline RIPM $15 \%$ & 1,67 & 0,13 & 7,63 & 5,18 & 0,20 & 3,80 & 7,26 & 0,68 & 9,34 \\
\hline RCD 5\% & 1,62 & 0,09 & 5,38 & 6,25 & 0,43 & 6,92 & 10,03 & 0,79 & 7,90 \\
\hline RCD $10 \%$ & 1,52 & 0,13 & 8,40 & 5,09 & 0,25 & 4,97 & 8,54 & 0,60 & 7,06 \\
\hline RCD $15 \%$ & 1,52 & 0,06 & 4,23 & 5,09 & 0,32 & 6,38 & 8,67 & 0,45 & 5,20 \\
\hline
\end{tabular}

Fonte: Autores (2021).

A Figura 3 traz a comparação entre os dados de resistência à compressão de cada traço, em cada uma das idades. 
Figura 3. Resistência à compressão das argamassas em todas as idades.

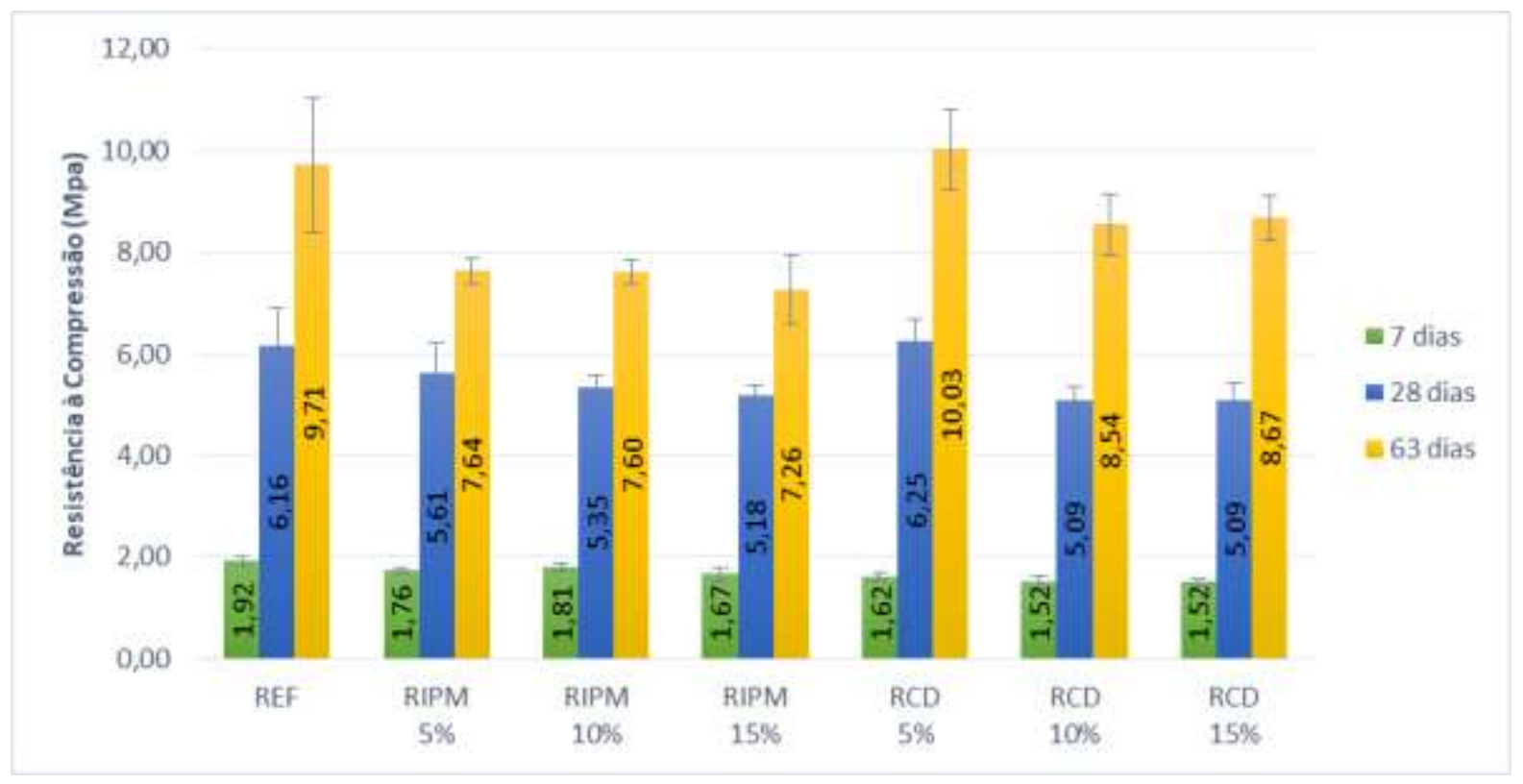

Fonte: Autores (2021).

Ao analisar os dados de resistência à compressão aos 7 dias, verifica-se que o maior valor foi registrado pelo traço de referência. Entre as argamassas que utilizaram resíduos em sua confecção, percebe-se que aquelas confeccionadas com RIPM obtiveram melhor desempenho, sendo que o teor de substituição de $10 \%$ apresentou maior resistência. Os grupos de argamassas RIPM 5\% e RCD 15\% apresentaram o menor desvio padrão, o que indica uma amostra homogênea e com valores próximos à média do grupo.

Aos 28 dias, o melhor desempenho foi registrado pelo traço RCD 5\%, com resistência 1,4\% maior que o traço de referência. Carasek, Araújo, Cascudo e Angelim (2016) constataram em seu estudo que o tamanho e formato das partículas influenciam no empacotamento granulométrico da argamassa, que por sua vez contribui para a redução dos espaços vazios entre os grãos, e aumento do índice de consistência. Observa-se que o traço RCD 5\% apresentou comportamento parecido ao do estudo mencionado, em que o fechamento do pacote granulométrico proporcionou redução da quantidade de água para atender o índice de consistência estipulado $(260 \mathrm{~mm} \pm 5 \mathrm{~mm})$, acarretando o acréscimo de resistência à compressão dessas misturas. Já os teores de substituição de RCD 10\% e RCD 15\% apresentaram a mesma média de resistência à compressão e um baixo coeficiente de variação, o que indica que o intervalo de substituição apresenta o mesmo desempenho. Também registrouse uma pequena variação nesse mesmo intervalo de substituição para os traços que utilizaram o RIPM em sua confecção. Segundo os requisitos da NBR 13281/2005 (Argamassa para assentamento e revestimento de paredes e tetos - Requisitos), as argamassas REF e RCD 5\% podem ser classificadas na Classe P5 (5,5 a 9,0 MPa) e as demais se categorizam como classe P4 (4,0 a 6,5 MPa), demonstrando que os traços propostos resultam em argamassas de boa qualidade quanto a esse parâmetro.

Aos 63 dias observa-se um comportamento similar ao apresentado com 28 dias. O melhor desempenho foi registrado pelo traço RCD 5\%, que apresentou resistência 3,3\% maior que o traço de referência. Entre as argamassas que utilizaram resíduos em sua composição, verifica-se que aquelas com RCD apresentam valores de resistência mais elevados que aquelas com RIPM. No entanto, embora os traços com RIPM tenham apresentado menor desempenho, as argamassas com 5 e $10 \%$ de RIPM apresentaram o menor desvio padrão e coeficiente de variação.

No estudo de Araújo (2014), embora o autor tenha testado o efeito do resíduo de construção civil como substituinte parcial do agregado e tenha usado teor de substituição de 0 a 100\%, com intervalo de $20 \%$ entre os traços, observa-se que a 
resistência inicial (aos 7 dias) apresentou valores inferiores aos das argamassas com RIPM e RCD. Neste estudo, o autor registrou a resistência de 1,71 MPa para a argamassa de referência e entre os traços que utilizaram resíduos, sendo que os melhores desempenhos foram obtidos pelos teores de 20 e 100\%, nesta ordem, com resistência de 1,39 e 1,42 MPa.

Os valores de resistência à compressão aos 28 dias são semelhantes aos do estudo de Pimentel, Pissolato, Jacintho e Martins (2018), com substituição de 30 e 60\% da areia por resíduos de construção civil. Os autores registraram o valor de 6,36 MPa para a argamassa de referência e 5,16 e 3,71 MPa para as substituições de 30 e 60\%, respectivamente.

A Tabela 8 apresenta os resultados da análise de variância (ANOVA) para a resistência à compressão. De acordo com esta análise, as variáveis relacionadas, teor de substituição e idade das amostras, apresentam significância estatística.

Tabela 8. Resultados da ANOVA - Resistência à compressão para todas as idades.

\begin{tabular}{ccccccc}
\hline Fonte & $\begin{array}{c}\text { Soma } \\
\text { Quadrada }\end{array}$ & G.L & $\begin{array}{c}\text { Média } \\
\text { Quadrada }\end{array}$ & F calculado & P -valor & F crítico \\
\hline Traços & 18,178 & 6 & 3,030 & 12,910 & $1,87 \mathrm{E}-09$ & 2,246 \\
\hline Idades & 652,610 & 2 & 326,304 & 1390,436 & $7,6 \mathrm{E}-53$ & 3,143 \\
\hline Traço x Idades & 16,033 & 12 & 1,336 & 5,693 & $1,6 \mathrm{E}-06$ & 1,909 \\
\cline { 1 - 4 } Resíduos & 14,785 & 63 & 0,235 & & & \\
\hline
\end{tabular}

Fonte: Autores (2021).

A análise de variância indicou a existência de pelo menos uma diferença significativa entre as médias. Desta forma, para identificar estas diferenças, realizou-se o teste de Tukey com um nível de confiabilidade de $95 \%$.

No teste de Tukey, constata-se que aos 7 dias não há diferença significativa entre as médias dos teores de substituição dentro do grupo de argamassas com RCD e RIPM. Já a comparação entre os grupos REF e RIPM apontou diferença significativa entre o REF e RIPM 15\% e entre os grupos REF e RCD todos os traços de substituição demonstraram diferenças significativas. A análise entre os grupos RIPM e RCD não verificou diferenças significativas para as comparações RIPM 5\% e RCD 5\%; RIPM 10\% e RCD 5\%; RIPM 15\% e RCD 5\%; RIPM 15\% e RCD 10\% e; RIPM 15\% e RCD 15\%.

Em relação a análise aos 28 dias, os resultados demonstram que há diferença significativa às aferições do traço REF com o traço RCD $10 \%$, e traço RCD 15\%. As comparações dentro do grupo de argamassas com RCD em sua composição demonstraram diferença significativa do RCD 5\% quando comparado ao RCD 10\% e RCD 15\%. Entre os grupos que utilizaram resíduos em sua composição, contatou-se que apenas a comparação do RIPM 15\% com o RCD 5\% apresentou diferença significativa, o que indica que os demais traços apresentam estatisticamente a mesma resistência. Também se enquadram na hipótese de igualdade entre as médias as comparações das argamassas elaboradas com RIPM e o traço de referência.

Já aos 63 dias, a análise de Tukey indica a existência de diferença significativa entre os grupos REF e RIPM para todos os teores de substituição. Nos grupos RCD e RIPM verificou-se desigualdade para as aferições entre RIPM 10\% e RCD 5\% e RIPM 15\% e RCD 5\%. Observa-se que, o grupo de argamassas que utilizou RCD em sua composição apresentou estatisticamente a mesma resistência daquelas do grupo de referência.

Os resultados do ensaio de resistência à tração na flexão demonstram que as argamassas que utilizaram resíduos em sua composição apresentaram melhor desempenho que a argamassa de referência. Observa-se que as argamassas com RCD apresentaram comportamento não linear entre o teor de substituição e a resistência à tração na flexão, e que o melhor rendimento foi registrado para o teor de $10 \%$ de substituição, com acréscimo de resistência de $62 \%$ em relação ao traço de referência. Já entre o grupo de argamassa com RIPM, registrou-se o melhor desempenho para o teor de substituição de 5\%, 
com aumento de resistência de $89 \%$ em relação ao traço de referência. Neste mesmo grupo, os teores de 10 e $15 \%$ registraram o mesmo valor de resistência, sendo $77 \%$ mais elevada que o traço de referência.

O resultado da média, desvio padrão e coeficiente de variação do ensaio de resistência à tração na flexão pode ser verificado na Tabela 9.

Tabela 9. Resultados de resistência à tração na flexão aos 28 dias.

\begin{tabular}{cccc}
\hline Traço & Média (MPa) & Desvio Padrão (MPa) & Coef. de Variação (\%) \\
\hline REF & 2,23 & 0,15 & 6,66 \\
\hline RIPM 5\% & 4,21 & 0,39 & 9,35 \\
\hline RIPM 10\% & 3,95 & 0,91 & 22,90 \\
\hline RIPM 15\% & 3,95 & 0,39 & 9,96 \\
\hline RCD 5\% & 3,35 & 0,26 & 7,69 \\
\hline RCD 10\% & 3,61 & 0,45 & 12,37 \\
\hline RCD 15\% & 2,58 & 1,36 & 52,92 \\
\hline
\end{tabular}

Fonte: Autores (2021).

A Figura 4 mostra o gráfico com o resultado do ensaio de resistência à tração na flexão das argamassas testadas, em corpos de prova com 28 dias.

Figura 4. Resultados de resistência à tração na flexão aos 28 dias.

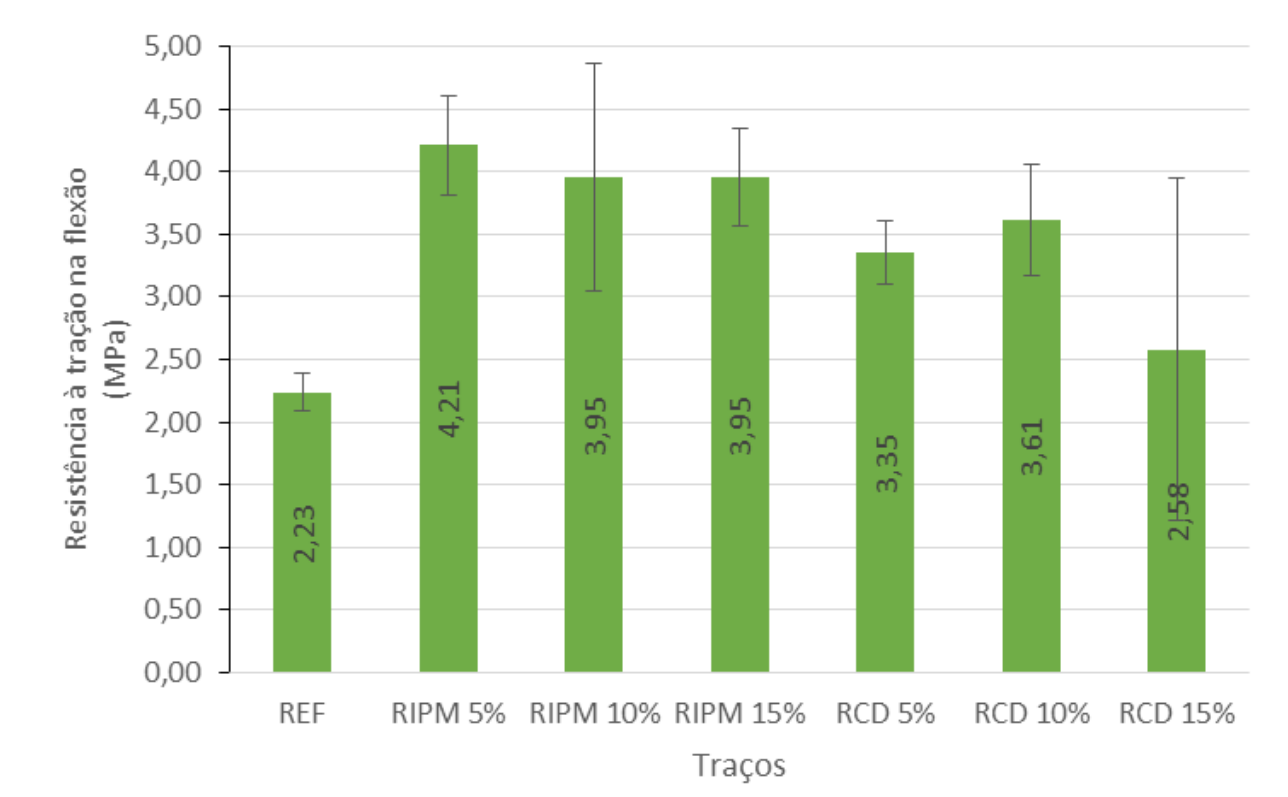

Fonte: Autores (2021).

Os resultados deste estudo caminham ao encontro com a pesquisa de Formigoni et al. (2019), com substituição do aglomerante por resíduo de placa cerâmica, onde se constatou o melhoramento da resistência de tração na flexão para os traços com substituição de até $12 \%$. Assim também, Pinz (2019) verificou que a utilização dos resíduos de cerâmica vermelha proporciona melhor desempenho à tração na flexão das argamassas, sendo que o melhor rendimento foi registrado com o teor de substituição de $15 \%$. 
A análise de variância indicou diferença estatística entre os resultados do ensaio de tração na flexão. A Tabela 10 apresenta o resultado desta análise. Desta forma, realizou-se então o teste de Tukey com confiabilidade de 95\% para identificar as diferenças. Os resultados deste teste evidenciaram a desigualdade entre a aferição do traço de referência e o traço RIPM 5\%.

Tabela 10. Resultados da ANOVA - Resistência à tração na flexão aos 28 dias.

\begin{tabular}{ccccccc}
\hline Fonte & $\begin{array}{c}\text { Soma } \\
\text { Quadrada }\end{array}$ & G.L & $\begin{array}{c}\text { Média } \\
\text { Quadrada }\end{array}$ & F calculado & P -valor & F crítico \\
\cline { 1 - 5 } Traços & 10,046 & 6 & 1,674 & \multirow{2}{*}{3,574} & 0,023 & 2,848 \\
\cline { 1 - 5 } Resíduos & 6,558 & 14 & 0,468 & & & \\
\hline
\end{tabular}

Fonte: Autores (2021).

Seguindo as indicações da NBR 13281/2005 (Argamassa para assentamento e revestimento de paredes e tetos Requisitos), as argamassas com RIPM em sua composição se enquadram na classe R6 (> 3,5 MPa). Já, as argamassas com teor de 5 e 10\% de RCD pertencem à classe R5 (2,7 a 4,5 MPa) e o teor de 15\% de RCD e a argamassa de referência, podem ser classificados como R4 (2,0 a 3,5 MPa).

Desta forma, no que diz respeito à resistência à tração na flexão, pode-se dizer que tanto o RCD quanto o RIPM como substituinte parcial do cimento propiciam a confecção de argamassas com desempenho igual ou superior à argamassa de referência, viabilizando a substituição de até $15 \%$ do cimento por estes resíduos.

\subsection{Desempenho físico}

O resultado do ensaio de absorção por capilaridade na idade de 28 dias demonstrou que as argamassas confeccionadas com RCD apresentam índices de absorção superiores aos das argamassas confeccionadas com RIPM. Este comportamento está relacionado com a maior porosidade do RCD, fato evidenciado durante o ensaio de caracterização, em que o material apresentou maiores coeficientes de absorção. Outro fato a se observar é que as argamassas confeccionadas com RIPM apresentaram a mesma média de absorção para os três teores de substituição. No entanto, cabe destacar que o traço RIPM 10\% apresentou o menor desvio padrão entre o grupo, o que indica que os valores foram mais homogêneos.

Entre as misturas que utilizaram RCD, os resultados foram descontínuos, pois o teor de $10 \%$ apresentou o melhor desempenho. Fato similar foi verificado na pesquisa de Canova (2017), onde o autor testou a substituição do cimento por finos de britagem. Neste estudo, os coeficientes de absorção também foram descontínuos, sendo que as substituições de 5 e $20 \%$ apresentaram índices de absorção superiores ao teor de $10 \%$.

A Tabela 11 apresenta o valor de média, desvio padrão e coeficiente de variação das argamassas estudadas. 
Tabela 11. Resultados de absorção por capilaridade aos 28 dias

\begin{tabular}{cccc}
\hline Traço & Média $\left(\mathrm{g} / \mathrm{cm}^{2}\right)$ & Desvio Padrão $\left(\mathrm{g} / \mathrm{cm}^{2}\right)$ & Coef. de Variação $(\%)$ \\
\hline REF & 2,55 & 0,02 & 0,61 \\
\hline RIMP 5\% & 2,60 & 0,05 & 1,82 \\
\hline RIMP 10\% & 2,60 & 0,02 & 0,60 \\
\hline RIMP 15\% & 2,60 & 0,03 & 1,26 \\
\hline RCD 5\% & 2,66 & 0,01 & 0,55 \\
\hline RCD 10\% & 2,62 & 0,02 & 0,88 \\
\hline RCD 15\% & 2,65 & 0,06 & 2,21 \\
\hline
\end{tabular}

Fonte: Autores (2021).

O gráfico apresentado na Figura 5, confeccionado com os dados da Tabela 11, exibe o resultado de absorção por capilaridade aos 28 dias.

Figura 5. Absorção de água por capilaridade das argamassas aos 28 dias

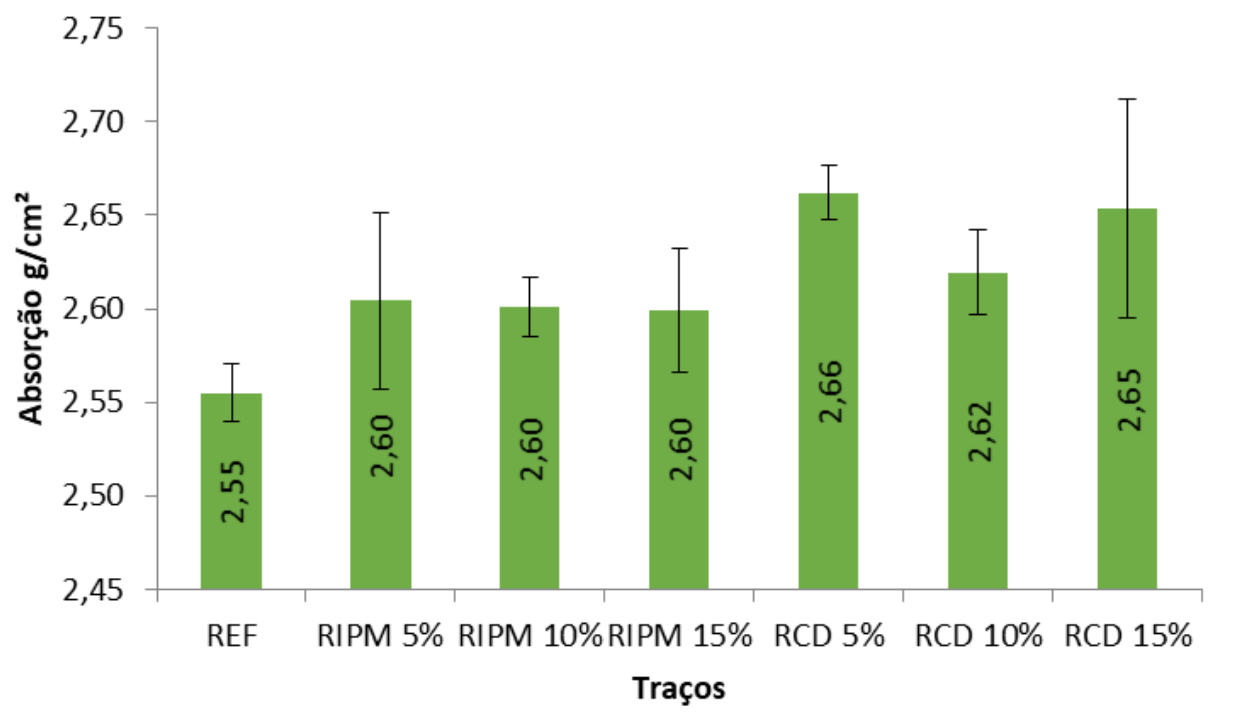

Fonte: Autores (2021).

Ao realizar a análise estatística constatou-se diferença significativa entre pelo menos uma das misturas, como verificase na Tabela 12. Com o intuito de conhecer esta diferença, realizou-se o teste de Tukey que identificou desigualdade do traço referência em relação ao traço RCD 5\%, e ao traço RCD 15\%. As outras substituições corresponderam a hipótese de igualdade entre as médias com o traço de referência. Sendo assim, pode-se concluir que o traço RCD 10\% e os três teores de substituição do RIPM não causam real interferência nas argamassas, viabilizando a sua utilização.

Tabela 12. Resultados da ANOVA - absorção por capilaridade aos 28 dias.

\begin{tabular}{ccccccc}
\hline Fonte & $\begin{array}{c}\text { Soma } \\
\text { Quadrada }\end{array}$ & G.L & $\begin{array}{c}\text { Média } \\
\text { Quadrada }\end{array}$ & $\begin{array}{c}\text { F } \\
\text { calculado }\end{array}$ & P -valor & F crítico \\
\hline Traços & 0,024 & 6 & 0,004 & 3,442 & 0,027 & 2,848 \\
\cline { 1 - 5 } Resíduos & 0,016 & 14 & 0,001 & & & \\
\hline
\end{tabular}

Fonte: Autores (2021). 
Já o ensaio de absorção de água por imersão e índices de vazios reafirma que a utilização dos resíduos em argamassas proporciona a redução dos espaços vazios entre os grãos da mistura, sendo o traço RCD 5\% o que apresentou o menor índice de vazios entre as argamassas estudadas. Em relação ao índice de absorção por imersão o traço RCD 10\% apresentou o menor percentual de absorção entre as misturas. Os resultados deste ensaio podem ser constatados na Tabela 13.

Tabela 13. Resultados de absorção por Imersão e Índices de Vazios aos 28 dias

\begin{tabular}{ccccccc}
\hline \multirow{2}{*}{ Traço } & \multicolumn{3}{c}{ Absorção (\%) } & \multicolumn{3}{c}{ Índice de Vazios (\%) } \\
\cline { 2 - 7 } & Média & $\begin{array}{c}\text { Desvio } \\
\text { Padrão }\end{array}$ & $\begin{array}{c}\text { Coef. de } \\
\text { Variação }\end{array}$ & Média & $\begin{array}{c}\text { Desvio } \\
\text { Padrão }\end{array}$ & $\begin{array}{c}\text { Coef. de } \\
\text { Variação }\end{array}$ \\
\hline REF & 15,69 & 0,38 & 2,40 & 28,82 & 0,58 & 2,00 \\
\hline RIMP 5\% & 15,16 & 0,15 & 0,99 & 27,99 & 0,17 & 0,62 \\
\hline RIMP 10\% & 14,99 & 0,51 & 3,43 & 27,81 & 0,74 & 2,65 \\
\hline RIMP 15\% & 15,22 & 0,27 & 1,80 & 28,18 & 0,37 & 1,30 \\
\hline RCD 5\% & 14,81 & 0,28 & 1,91 & 27,59 & 0,39 & 1,40 \\
\hline RCD 10\% & 14,79 & 0,27 & 1,81 & 27,64 & 0,41 & 1,47 \\
\hline RCD 15\% & 14,91 & 0,06 & 0,41 & 27,75 & 0,15 & 0,54 \\
\hline
\end{tabular}

Fonte: Autores (2021).

O gráfico apresentado na Figura 6, elaborado com os dados da Tabela 13, apresenta o resultado de absorção por imersão e índices de vazio 28 dias.

Figura 6. Absorção de água por imersão e índices de vazios aos 28 dias.

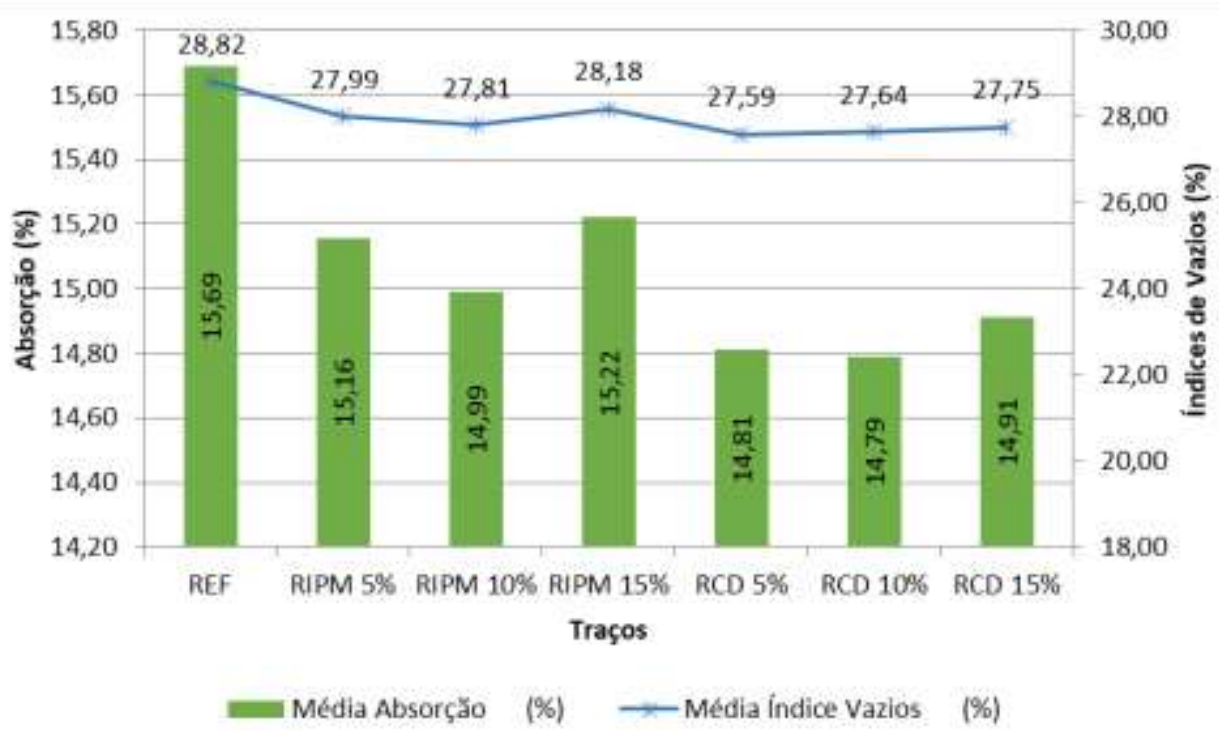

Fonte: Autores (2021).

No entanto, através da análise de variância constatou-se que não há diferenças estatísticas entre as médias das argamassas analisadas, conforme verifica-se na Tabela 14 e Tabela 15. 
Tabela 14. Resultados da ANOVA - absorção por imersão aos 28 dias.

\begin{tabular}{ccccccc}
\hline Fonte & $\begin{array}{c}\text { Soma } \\
\text { Quadrada }\end{array}$ & G.L & $\begin{array}{c}\text { Média } \\
\text { Quadrada }\end{array}$ & F calculado & P -valor & F crítico \\
\cline { 1 - 5 } Traços & 1,180 & 6 & 0,197 & 2,088 & 0,177 & 3,866 \\
\cline { 1 - 5 } Resíduos & 0,659 & 7 & 0,094 & & & \\
\hline
\end{tabular}

Fonte: Autores (2021).

Tabela 15. Resultados da ANOVA - Índices de Vazios aos 28 dias.

\begin{tabular}{ccccccc}
\hline Fonte & $\begin{array}{c}\text { Soma } \\
\text { Quadrada }\end{array}$ & G.L & $\begin{array}{c}\text { Média } \\
\text { Quadrada }\end{array}$ & F calculado & P -valor & F crítico \\
\cline { 1 - 5 } Traços & 2,199 & 6 & 0,366 & 1,862 & 0,217 & 3,866 \\
\cline { 1 - 5 } Resíduos & 1,378 & 7 & 0,197 & & & \\
\hline
\end{tabular}

Fonte: Autores (2021).

Os resultados encontrados reiteram o estudo de Pinz (2019), em que a autora apurou que a substituição do cimento por resíduo de cerâmica vermelha, nos teores de 5 e 15\%, não causam real interferência na absorção por imersão e índice de vazios de argamassas mistas.

\section{Conclusão}

Ao analisar os resultados da incorporação da fração cimentícia dos resíduos de construção civil como substituintes do cimento em argamassas, pode-se tecer as conclusões descritas abaixo.

Embora a adição do RCD em argamassas tenha proporcionado a redução da resistência à compressão aos sete dias, observa-se que as argamassas com incorporação deste resíduo apresentaram, ao longo do tempo, bom desempenho mecânico, sendo que as argamassas confeccionadas com 5\% de RCD são estatisticamente iguais às argamassas de referência aos 28 dias, e aos 63 dias os três teores de substituição proporcionam argamassas estatisticamente equivalentes ao traço de referência. Em relação às argamassas desenvolvidas com RIPM, observa-se que as argamassas alternativas apresentaram igualdade estatística nas idades de 7 e 28 dias, e embora tenham apresentado rendimento inferior ao traço de referência na idade de 63 dias, os valores de resistência à compressão foram satisfatórios.

No que diz respeito à resistência à tração na flexão, os resultados obtidos mostraram que a incorporação de resíduos melhorou o desempenho das argamassas. O teor de substituição de 5\% do RIPM apresentou aumento de resistência de $89 \%$ em relação ao traço de referência, e os demais traços foram considerados estatisticamente iguais ao traço de referência.

Em relação ao ensaio de absorção por capilaridade verifica-se que o traço RCD $10 \%$ e os três teores de substituição do RIPM não causaram real interferência nas argamassas, pois proporcionam misturas com o mesmo desempenho que as argamassas de referência. Quanto aos ensaios de absorção por imersão e índices de vazios os resultados indicaram que tanto as argamassas confeccionadas com RIPM quanto as argamassas com RCD apresentaram estatisticamente o mesmo desempenho que a argamassa de referência.

Desta maneira, considerando a análise dos dados, concluir-se que a incorporação de ambos os resíduos é uma alternativa viável, pois proporcionam argamassas com desempenho equivalente ao da argamassa de referência. No entanto, considerando que não é recomendado um alto índice de absorção por capilaridade em argamassas de revestimento, indica-se a utilização do teor de $10 \%$ do RCD. Já em relação ao RIPM, podem ser aplicados os três teores de substituição sem nenhuma interferência nas argamassas. 


\section{Referências}

ABNT NBR 10007, de 31 de maio de 2004. Amostra de resíduos sólidos. Associação Brasileira de Normas Técnicas.

ABNT NBR 13276, de 28 de setembro de 2016. Argamassa para assentamento e revestimento de paredes e tetos - Determinação do índice de consistência. Associação Brasileira de Normas Técnicas.

ABNT NBR 13279, de 30 de setembro de 2005. Argamassa para assentamento e revestimento de paredes e tetos - Determinação da resistência à tração na flexão e à compressão. Associação Brasileira de Normas Técnicas.

ABNT NBR 13281, de 30 de setembro de 2005. Argamassa para assentamento e revestimento de paredes e tetos - Requisitos. Associação Brasileira de Normas Técnicas.

ABNT NBR 7214, de 16 de novembro de 2015. Areia normal para ensaio de cimento - Especificação. Rio de Janeiro: Associação Brasileira de Normas Técnicas.

ABNT NBR 7215, de 28 de fevereiro de 2019. Cimento Portland - Determinação da resistência à compressão de corpos de prova cilíndricos. Associação Brasileira de Normas Técnicas.

ABNT NBR 9778, de 29 de setembro de 2009. Argamassa e concreto endurecidos - Determinação da absorção de água, índice de vazios e massa específica. Associação Brasileira de Normas Técnicas.

ABNT NBR 9779, de 10 de dezembro de 2012. Argamassa e concreto endurecidos — Determinação da absorção de água por capilaridade. Associação Brasileira de Normas Técnicas.

ABNT NBR NM 248, de 01 de setembro de 2003. Agregados - Determinação da composição granulométrica. Associação Brasileira de Normas Técnicas.

ABNT NBR NM 30, de 30 de maio de 2001. Agregado miúdo - Determinação da absorção de água. Associação Brasileira de Normas Técnicas.

ABNT NBR NM 45, de 31 de março de 2006. Agregados - Determinação da massa unitária e do volume de vazios. Associação Brasileira de Normas Técnicas.

ABNT NBR NM 52, de 30 de outubro de 2009. Agregado miúdo - Determinação da massa específica e massa específica aparente. Associação Brasileira de Normas Técnicas.

Araújo, N. N. (2014). Desempenho de argamassas de revestimento produzidas com agregados reciclados oriundos do resíduo de construção e demolição da Grande Natal-RN (Dissertação de mestrado). Programa de Pós-Graduação em Engenharia Civil, Universidade Federal do Rio Grande do Norte, Natal, RN, Brasil.

Associação Brasileira de Empresas de Limpeza Pública e Resíduos Especiais (2020). Panorama dos resíduos sólidos no Brasil 2020. https://abrelpe.org.br/panorama-2020/. Acesso em: 31/05/21.

Braga, M., Brito, J., \& Veiga, R. (2014). Reduction of the cement content in mortars made with fine concrete aggregates. Materials and Structures, 47, 171182.

Canova, J. A. (2017). Substituição do cimento por finos de britagem em argamassa de revestimento. Revista Ciência \& Engenharia, 26, (2), 11-26.

Carasek, H., Araújo, R. C., Cascudo, O., \& Angelim, R. (2016). Parâmetros da areia que influenciam a consistência e a densidade de massa das argamassas de revestimento. Revista Matéria, 21 (3), 714-732.

Evangelista, L., Guedes, M., Brito, J., Ferro, A.C., \& Pereira, M.F. (2015). Propriedades físicas, químicas e mineralógicas de agregados finos reciclados feitos de resíduos de concreto. Construction and Building Materials, 86, 178-188.

Fonseca, M. J. M., \& Maintinguer, S. I. (2019). Aplicação da logística reversa na construção civil como mecanismo ambiental sustentável em políticas públicas. Brazilian Journal of Development, 5 (1), 140-149.

Formigoni, W. F., Godinho, D. S. S., Junca, E., \& Antunes, E. G. P. (2019). Substituição do cimento Portland por resíduo de placa cerâmica em argamassa. Revista Tecnologia em Metalurgia, Materiais e Mineração, 16 (1), 62-67.

Jochem, L. F. (2012). Estudo das argamassas de revestimento com RCD (Dissertação de mestrado). Programa de Pós-Graduação em Engenharia Civil, Universidade Federal de Santa Catarina, Florianópolis, SC, Brasil.

Jochem, L. F. (2017). Efeito do agregado reciclado dos resíduos de construção e demolição na retenção dos metais pesados em processos de solidificação e estabilização (Tese de doutorado). Programa de Pós-Graduação em Engenharia Civil, Universidade Federal de Santa Catarina, Florianópolis, SC, Brasil.

Oliveira, L. J. C., Soares, M. C. B., Quaresma, W. M. G., \& Adorno, A. L. C. (2020). Gestão de resíduos: uma análise sobre os impactos da geração de rejeitos na construção civil. Brazilian Journal of Development, 6 (5), 24447-24462.

Pimentel, L. L., Pissolato, O. J., Jacintho, A. E. P. G. A., \& Martins, H. L. S. (2018). Argamassa com areia proveniente da britagem de resíduo de construção civil - avaliação de características físicas e mecânicas. Revista Matéria, 23 (1).

Pinz, F. P. (2019). Influência do resíduo de cerâmica vermelha em argamassas na substituição parcial do agregado ou do cimento (Dissertação de mestrado). Programa de Pós-Graduação em Arquitetura e Urbanismo, Universidade Federal de Pelotas, Pelotas, RS, Brasil.

Pinz, F.P., Paliga, C. M., \& Torres, A. T. (2020). Estudo da influência do resíduo de cerâmica vermelha, como substituinte parcial ao aglomerante ou ao agregado, em argamassas mistas para revestimento. Research, Society and Development, 9 (11). 
Research, Society and Development, v. 10, n. 8, e31410817342, 2021

(CC BY 4.0) | ISSN 2525-3409 | DOI: http://dx.doi.org/10.33448/rsd-v10i8.17342

Ribeiro, D., Moura, L. S., \& Pirote, N. S. S. (2016). Sustentabilidade: Formas de Reaproveitar os Resíduos da Construção Civil. Revista Ciências Gerenciais, $20(31), 41-45$.

Samadi, M., Huseien, G. F., Mohammadhosseini, H., Lee, H, S., Lim, N. H. A. S., Tahir, M., \& Alyousef, R. (2020). Waste ceramic as low cost and ecofriendly materials in the production of sustainable mortars. Journal of Cleaner Production, 266.

Vieira, B. A., \& Nogueira, L. (2018). Construção Civil: Crescimento versus custos de produção civil. Sistema \& Gestão, 13 (3), $366-377$. https://www.revistasg.uff.br/sg/article/view/1419

Wichrowska, K. K., Kazberuk, M. K., \& Pawluczuk, E. (2020). The properties of composites with recycled cement mortar used as a supplementary cementitious material. Materials, 13 (64). 